\title{
Knockdown of PRKAR2B Results in the Failure of Oocyte Maturation
}

\author{
Hyemin Yoon ${ }^{a}$ Hoon Jang ${ }^{a}$ Eun-Young Kima Sohyeon Moon ${ }^{a}$ Sangho Lee \\ Minha Cho ${ }^{a}$ Hye Jung Cho ${ }^{b}$ Jung Jae Ko ${ }^{a, c}$ Eun Mi Chang ${ }^{c} \quad K_{y u n g}-A h L^{2} e^{a}$ \\ Youngsok Choi $\mathrm{i}^{\mathrm{a}, \mathrm{c}}$ \\ aDepartment of Biomedical Science, CHA University, Seongnam-si, Gyeonggi-do, ${ }^{b}$ Department of \\ Medicine, CHA University, Seongnam-si, Gyeonggi-do, 'Fertility Center of CHA Gangnam Medical \\ Center, CHA University, Seoul, Republic of Korea
}

\section{Key Words}

Prkar2b - Oocyte maturation - MI arrest - Pentose phosphate pathway • cAMP-dependent protein kinase $\mathrm{A}$

\begin{abstract}
Background/Aims: Cyclic adenosine monophosphate (CAMP)-dependent type 2 regulatory subunit beta (Prkar2b) is a regulatory isoform of cAMP-dependent protein kinase (PKA), which is the primary target for CAMP actions. In oocytes, PKA and the pentose phosphate pathway (PPP) have important roles during the germinal vesicle (GV) stage arrest of development. Although the roles of the PKA signal pathway have been studied in the development of oocyte, there has been no report on the function of PRKAR2B, a key regulator of PKA. Methods: Using reverse transcription polymerase chain reaction (RT-PCR), quantitative real-time PCR (qRT-PCR), immunohistochemistry, and immunofluorescence, we determined the relative expression of Prkar2b in various tissues, including ovarian follicles, during oocyte maturation. Prkar2b-interfering RNA (RNAi) microinjection was conducted to confirm the effect of Prkar2b knockdown, and immunofluorescence, qRT-PCR, and time-lapse video microscopy were used to analyze Prkar2b-deficient oocytes. Results: Prkar2b is strongly expressed in the ovarian tissues, particularly in the growing follicle. During oocyte maturation, the highest expression of Prkar2b was during metaphase I (MI), with a significant decrease at metaphase II (MII). RNAi-mediated Prkar2b suppression resulted in MI-stage arrest during oocyte development, and these oocytes exhibited abnormal spindle formation and chromosome aggregation. Expression of other members of the PKA family (except for Prkaca) were decreased, and the majority of the PPP factors were also reduced in Prkar2b-deficient oocytes. Conclusion: These results suggest that Prkar2b is closely involved in the maturation of oocytes by controlling spindle formation and PPP-mediated metabolism.
\end{abstract}

$\mathrm{H}$. Yoon and H. Jang contributed equally to this work.

\begin{tabular}{ll}
\hline Youngsok Choi Ph.D., & Department of Biomedical Science, CHA University, \\
Kyung-Ah Lee, Ph.D. & 335 Pangyo-ro, Bundang-gu, Seongnam-si, Gyeonggi-do (Republic of Korea) \\
and Eun Mi Chang, M.D. & E-Mail youngsokchoi@cha.ac.kr, leeka@cha.ac.kr, emchang@cha.ac.kr
\end{tabular}




\section{Introduction}

Cyclic adenosine monophosphate (cAMP)-dependent protein kinase (PKA) is the chief mediator of cAMP in a variety of mammalian cells $[1,2]$. PKA is a well-studied holoenzyme of the protein kinase family $[3,4]$, which functions as a hetero-tetramer form consisting of two catalytic (C) and two regulatory (R) subunits [5]. Murine PKA is comprised of four R subunits $(\mathrm{RI} \alpha, \mathrm{RI} \beta$, RII $\alpha$, and $\mathrm{RII} \beta)$ and two $\mathrm{C}$ subunits $(\mathrm{C} \alpha$ and $\mathrm{C} \beta)[3,4]$. When cAMP is bound to two sites of each $\mathrm{R}$ subunit, the $\mathrm{C}$ subunits separate, inducing phosphorylation of the Ser/ Thr residues of the target protein $[3,6]$. Included in the PKA family is cAMP-dependent type 2 regulatory subunit beta (Prkar $2 b$ ), a form of RII $\beta$; these genes are primarily expressed in brain tissue, brown adipose tissue, and white adipose tissue $[7,8]$. Prkar2 $b$ has the ability to regulate leukemia cell differentiation [9], plays a role in motoneurons [10] and alternative signaling of cAMP pathways [11], suppresses the effect of cAMP responsive element binding protein (CREB) activity in T cells [12], regulates adipocyte differentiation [13], and plays an oncogenic role in prostate cancer [14]. A recent study found that Prkar2b-deficient mice experience a decrease in white adipose tissue and an increase in resting metabolic activity, body temperature, and lipid hydrolysis [7]. However, only a small number of studies have investigated PRKAR2B signaling; the role of PRKAR2B in oocyte development has not yet been elucidated.

Various cellular processes are controlled by cAMP, including cell growth, differentiation, ion channel conductivity, synaptic release of neurotransmitters, and gene transcription [15], and is used as a second messenger in cells and for activation of different cAMP receptor molecules, which consist of ion channels and several PKA holoenzymes [15]. During oocyte maturation, cAMP-PKA signaling plays an important role in the regulation of meiosis [16]. A high concentration of cAMP activates PKA and arrests the oocyte in the GV stage, whereas decreased cAMP results in inactivation of PKA and resumption of meiosis [17]. Although PRKAR2B is part of the PKA family of proteins and is highly expressed in ovarian follicles, its role in oocyte maturation has not yet been determined.

Oocyte developmental processes are highly complex and dynamically regulated by various factors such as luteinizing hormone, anti-Müllerian hormone, and follicle stimulating hormone during folliculogenesis [18-21]. In ovarian follicles, the oocyte is present in the diplotene dictyate stage until development of the pre-ovulatory follicle [22-24]. At ovulation, the oocyte is in a state of germinal vesicle (GV) arrest. During oocyte maturation, the oocyte enters the GV breakdown (GVBD) stage and then serially undergoes further meiotic divisions (metaphase I [MI] and metaphase II [MII]) until secondary meiotic arrest at fertilization. As meiotic division of the oocyte progresses, the chromosomes and spindle migrate to the cortex, establishing asymmetric positioning and resulting in polarity of the oocyte, which is induced by signal pathway proteins including CDC42, RAC, ARP2/3 complex, and RASD1 [25-28]. Although several studies regarding significant processes during oocyte maturation have been performed, the detailed mechanisms of these processes, including the role of Prkar2b, have not yet been investigated. In this study, we determined the role of Prkar2b in mouse oocyte maturation.

\section{Materials and Methods}

\section{Animals}

All animal studies were carried out on 3- or 6-week-old ICR female mice and the total number of mice used in the study was approximately 100. Mice were housed in the Animal Care Facility of CHA University, maintained in a controlled environment, and supplied with a normal diet and water. Animal care was in compliance with the Guide for the Care and Use of Laboratory Animals and was approved by the Institutional Animal Care and Use Committee (IACUC N0.150047) of CHA University. 
Table 1. Primer sequences and RT-PCR conditions

\begin{tabular}{|c|c|c|c|c|}
\hline Genes & Accession No. & Primer sequences & Annealing temperature $\left({ }^{\circ} \mathrm{C}\right)$ & Product size (bp) \\
\hline Prkar2b (1) RT-PCR & NM_011158.3 & For - GACGATGCAGAGTCCAGGAT Rev - TCTCCTGAAGGTCACCCTGT & 60 & 384 \\
\hline Prkar2b (2) dsRNA & NM_011158.3 & For - CAGGAGAACGAGCGCAAG Rev - GGCCAGTTCTCCAAAACTCC & 60 & 549 \\
\hline PrKar 2b (3) confirm & NM_011158.3 & For - GACGATGCAGAGTCCAGGAT Rev - CTCCTGAAGGTCACCCTGTC & 60 & 384 \\
\hline Prkaca & NM_008854.5 & For - GCAGATCGAGCACACTCTG Rev - GTAGGTGGGAGAACATCTCG & 60 & 149 \\
\hline Prkacb & NM_011100.4 & For - GGAGATCATCCTCAGCAAGG Rev - GCAGAAGGTCCTTGAGATCG & 60 & 188 \\
\hline Prkar1a & NM_001313975.1 & For - CAGAGCAGCCACTGTCAAAG Rev - TGCATCGGCTACTGTGAGAC & 60 & 181 \\
\hline Prkar1b & NM_001253890.1 & For - CGAGATGTACGTGCAGAAAC Rev - CACTGGGAGTTTGACTTCTG & 60 & 171 \\
\hline Prkar2a & NM_008924.2 & For - GCCAGGAATCAGACACGTTC Rev-CGTTATCCTCCTCTTCTTCATC & 60 & 204 \\
\hline Gpi1 & NM_008155.4 & For - GTGGTCAGCCATTGGACTTT Rev - CTGGAAATAGGCAGCAAAGC & 60 & 232 \\
\hline G6pd2 & NM_019468.3 & For - GCCTGGCATGTTCTTTAACC Rev - CAATCTTGTGCAGCAGTGGT & 60 & 194 \\
\hline Rpe & NM_001310642.1 & For - GGGCAGAAATTCATGGAAGA Rev - GTACTGCCAGACACAATCAT & 60 & 152 \\
\hline Rpia & NM_009075.2 & For - AAGATCGTGGCTGGTTATGC Rev - ACAGCCATTCGAAGTTCCAC & 60 & 182 \\
\hline Tkt & NM_009388.6 & For - TCCACCGTCTTTTACCCAAG Rev - CAAGGCCTCATGCAGAGTTA & 60 & 222 \\
\hline Taldo1 & NM_011528.4 & For - TGACGCTCATCTCTCCCTTT Rev - GGAGATGGTGAGGAAGTCAC & 60 & 221 \\
\hline Rbks & NM_153196.1 & For - AGTGGCTGGAGCAAATCTGT Rev - GCGTGGCCTGTTAAAATCTC & 60 & 261 \\
\hline Prps1 & NM_021463.4 & For - TTGATATCCCGGTGGACAAT Rev - ATAGCCACACGGTCCTTCAC & 60 & 238 \\
\hline Gapdh & NM_008854.5 & For - AGGTCGGTGTGAACGGATTTG Rev -TGTAGACCATGTAGTTGAGGT & 60 & 123 \\
\hline H1foo & BC092294 & For - GTTGCCGCAGAATCCAAGC Rev - GCTACAACTGATGTGCCCTGG & 60 & 103 \\
\hline
\end{tabular}

\section{RT-PCR and $q R T-P C R$}

Mouse tissues were isolated from 6-week-old mice and total RNA prepared using Trizol reagent (Invitrogen, USA) according to the manufacturer's manual. The complementary DNA (cDNA) was synthesized using the TOPscript ${ }^{\mathrm{TM}}$ cDNA Synthesis Kit (Enzynomics, Korea) according to the manufacturer's instruction. Reverse transcription polymerase chain reaction (RT-PCR) was carried out using Solg ${ }^{\mathrm{TM}}$ Taq DNA Polymerase (SolGent, Korea). PCR conditions and primer sequences are provided in Table 1. Quantitative real-time PCR (qRT-PCR) was performed using $\mathrm{iQ}^{\text {TM }}$ SYBR Green Supermix (Bio-Rad Laboratories, USA). Experiments were normalized with $\mathrm{H} 1$ histone family member 0 , oocyte specific (H1foo) and glyceraldehyde-3-phosphate dehydrogenase (Gapdh).

\section{Histology and immunostaining}

Six-week-old mouse ovaries were fixed with $4 \%$ formaldehyde for 2 days and embedded in paraffin. Sectioned samples ( $5 \mu \mathrm{m}$ thickness) were applied to slides (Fisher Scientific, USA) and dried overnight. Following deparaffinization with xylene, immunohistochemistry was performed as previously described using rabbit anti-PRKAR2B antibody (1:100 dilution, Abcam, UK, cat\# ab75993) [29].

Immunofluorescence was performed on mouse oocytes. The oocytes were washed 3 times with $0.1 \%$ polyvinyl alcohol in phosphate-buffered saline (PVA-PBS) at room temperature. Oocytes were then fixed in fixation solution (4\% paraformaldehyde in PVA-PBS) for 2 min and treated with permeabilization solution $(0.5 \%$ Triton X-100 in PVA-PBS) for $20 \mathrm{~min}$ at room temperature. Oocytes were washed 3 times with PVA-PBS and incubated in 1\% bovine serum albumin in PVA-PBS (1\% BSA-PVA-PBS) at $4^{\circ} \mathrm{C}$ overnight. The oocytes were then transferred to blocking solution (3\% BSA in PVA-PBS) for $1 \mathrm{~h}$ at room temperature. After blocking, oocytes were treated with anti-PRKAR2B (1:100 dilution, Abcam, cat\# ab75993) and anti- $\alpha$ tubulin (1:100 dilution, Santa Cruz Biotechnology, USA, cat\# sc-8035) in 1\% BSA-PVA-PBS at $4^{\circ} \mathrm{C}$ overnight. After washing 3 times in PVA-PBS, oocytes were incubated in secondary antibody conjugated to Alexa Fluor 546 immunoglobulin (IgG) (1:100 dilution, Invitrogen, cat\# A11001 and A11010) in 1\% BSA-PVA-PBS at $4^{\circ} \mathrm{C}$ for $1 \mathrm{~h}$. After washing, oocyte nuclei and F-actin were stained with 4',6-diamidino-2-phenylindole (DAPI) (1:200 dilution, D3571, Invitrogen) and phalloidin (1:200 dilution, Invitrogen, cat\# A12379), respectively, for $10 \mathrm{~min}$ at room temperature. Samples were then mounted with Malinol mounting medium (Muto, Japan).

\section{Preparation of dsRNA}

Partial sequences of the Prkar2b coding region were amplified using Prkar2b-specific primers (Table 1 ), and then cloned into pGEM-T Easy Vector (Promega, USA) for sense and anti-sense strands. Prkar2b clones were linearized with SpeI and sense or anti-sense RNAs were in vitro transcribed by T7 polymerase using the MEGAscript Kit (Ambion, USA). Sense and anti-sense strands were mixed, hybridized at $75^{\circ} \mathrm{C}$ for $5 \mathrm{~min}$, and then slowly cooled to room temperature. The remaining nucleic acids were removed with DNase I and RNase A. After ethanol precipitation, double-stranded RNA (dsRNA) was dissolved in Tris-EDTA (TE) buffer $(3.3 \mu \mathrm{g} / \mu \mathrm{l})$ and stored at $-80^{\circ} \mathrm{C}$.

\section{Collection and microinjection of oocytes and in vitro culture}

Three-week-old ICR female mice were intraperitoneally injected with 5 IU of pregnant mare serum gonadotropin (PMSG; Sigma-Aldrich, USA). After 43-45 h, mice were sacrificed and their ovaries isolated 


\section{Cellular Physiology Cell Physiol Biochem 2018;45:2009-2020

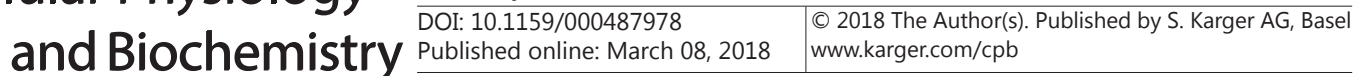

and maintained in M2 medium (Sigma-Aldrich) with $0.2 \mathrm{mM}$ 3-isobutyl-1-methylxanthine (IBMX; SigmaAldrich). Ovaries were pierced with a 26-gauge needle and cumulus-enclosed oocyte complexes (COCs) collected. Cumulus cells (CCs) were then removed from COCs and GV oocytes obtained using a fine-bore pipette. CCs and granulosa cells (GCs) were collected and stored at $-80^{\circ} \mathrm{C}$. Prkar2 $b$ dsRNA (10 pl of $3.3 \mu \mathrm{g} /$ $\mu \mathrm{l}$ ) was microinjected into the cytoplasm of the GV stage oocytes (in M2 medium with 0.2 mM IMBX). A constant-flow system (FemtoJet; Eppendorf, Germany) was used for microinjection. Green fluorescent protein (GFP) dsRNA was used as a control. Microinjected GV oocytes were cultured in $5 \% \mathrm{CO}_{2}$ at $37^{\circ} \mathrm{C}$ in M16 medium (Sigma-Aldrich) with $0.2 \mathrm{mM}$ IMBX in order to degrade the target transcript. After $8 \mathrm{~h}$, culture medium was replaced with M16 medium containing $3 \mathrm{mg} / \mathrm{ml}$ BSA (Sigma-Aldrich) and oocytes were incubated in $5 \% \mathrm{CO}_{2}$ at $37^{\circ} \mathrm{C}$ for $16 \mathrm{~h}$, after which the maturation rate was determined.

\section{Oocyte mRNA isolation and cDNA synthesis}

Oocyte messenger RNA (mRNA) preparation was accomplished using the Dynabeads mRNA DIRECT Kit (Dynal, Norway). Dynabeads oligo $(\mathrm{dT})_{25}$ beads $(10 \mu \mathrm{l})$ were prewashed by combining them with lysis/ binding buffer (100 mM Tris- $\mathrm{HCl}$ [pH 7.5], $500 \mathrm{mM} \mathrm{LiCl,} 10 \mathrm{mM}$ EDTA, 1\% LiDS, and 5 mM dithiothreitol [DTT]) $(300 \mu \mathrm{l})$. Oocytes were resuspended in the lysis/binding buffer, and then the prewashed Dynabeads oligo(dT $)_{25}$ were added to the oocyte lysate and incubated for $3 \mathrm{~min}$ at room temperature. The samples were then subjected to a Dynal magnetic particle concentrator (MPC)-S, the RNA-binding beads washed with buffer A (10 mM Tris-HCl [pH 7.5], $0.15 \mathrm{M} \mathrm{LiCl,} 1 \mathrm{M}$ EDTA, 0.1\% LiDS) followed by buffer B (10 mM Tris-HCl [pH 7.5], $0.15 \mathrm{M} \mathrm{LiCl}, 1 \mathrm{M}$ EDTA) for $1 \mathrm{~min}$ each at room temperature, and the beads were then pelleted under a magnetic field for $1 \mathrm{~min}$. The RNA was then eluted in $13 \mu \mathrm{l} 10 \mathrm{mM}$ Tris- $\mathrm{HCl}$ [pH 7.5] at $70^{\circ} \mathrm{C}$ for $3 \mathrm{~min}$. Eluted mRNA and $1 \mu \mathrm{l}$ oligo(dT) were combined and annealed at $70^{\circ} \mathrm{C}$ for 10 min using the TOPscript $^{\mathrm{TM}}$ cDNA Synthesis Kit (Enzynomics). After annealing, TOPscript ${ }^{\mathrm{TM}}$ Reverse Transcriptase (200 U/ ul), 10 $\times$ TOPscript $^{\mathrm{TM}}$ RT Buffer, dNTP mixture ( $2 \mathrm{mM}$ each nucleotide), and RNase inhibitor (40 U/ul) were added and cDNA was synthesized at $42^{\circ} \mathrm{C}$ for $60 \mathrm{~min}$. The reaction was halted by incubating at $95^{\circ} \mathrm{C}$ for 5 min.

Time lapse video microscopy

Time lapse video microscopy (JuLITM, Digital Bio, Korea) was used to determine the phenotype of the oocytes. Images of the oocytes in $37^{\circ} \mathrm{C} \mathrm{CO}_{2}$ incubator were captured every $5 \mathrm{~min}$ for $36 \mathrm{~h}$.

\section{Statistical analyses}

The experimental data were presented as the mean standard error of the mean (SEM). Real-time PCR data were analyzed using a one-way analysis of variance (ANOVA) for statistical evaluation. P-values were considered statistically significant.

\section{Results}

\section{Expression of Prkar2b mRNA in mouse tissues}

Because the dramatically changed genes during primordial follicle activation to primary follicles means that which play critical roles in ovarian follicle development, the expression levels of the whole genes in dormant follicles and growing follicles are analyzed using microarray analysis. Then, we selected the Prkar $2 b$, a novel and less studied regulator, among the 947 up-regulated genes in activated follicles. To compare the expression level of Prkar2b mRNA in mouse tissues, RT-PCR and qRT-PCR were performed using various tissues such as small intestine, stomach, kidney, spleen, heart, liver, lung, brain, ovary, uterus, and testis from 6-week old mice. The results showed that Prkar2b was highly expressed in the ovary (Fig. 1A and 1B). Additionally, to examine the expression levels of other PKA families in these tissues, alternative isoforms of PKA such as Prkar2a, Prkar1a, Prkar1b, Prkaca, and Prkacb were measured using RT-PCR, and the results indicated that only Prkar $2 b$ was highly expressed in mice ovary (Fig. 1A). To further study of Prkar2b, we tested the anti-Prkar2b antibody by western blotting using flag-conjugated Prkar2b cloning vector in Hek-293T cells. The results showed that both anti-flag and anti-Prkar2b detected the proteins (Fig. 1D). To 


\section{Cellular Physiology and Biochemistry}

Cell Physiol Biochem 2018;45:2009-2020

\begin{tabular}{l|l}
\hline DOI: 10.1159/000487978 & (C) 2018 The Author(s). Published by S. Karger AG, Basel
\end{tabular}

Yoon et al.: PRKAR2b in Oocyte Maturation

Fig. 1. Expression of protein kinase A family members mRNA and protein in mouse tissues. The mRNA was isolated from the tissues of 6-week-old mice. (A-B) RT-PCR and qRT-PCR analysis of protein kinase A family members transcript in mouse tissues (small intestine, stomach, kidney, spleen, heart, liver, lung, brain, ovary, uterus, and testis). Expression levels were normalized with Gapdh mRNA. Data are expressed as mean \pm SEM. (C) Immunohistochemical analysis of PRKAR2B in 6-week-old mouse ovary. Hematoxylin was used for nuclei staining. (D) Antibody test of Prkar2b for the experiment. Mouse Prkar2b gene was cloned into Flagtagged expression vector, and then transfected to hek293T cells for 48h. Western blot analysis showed that both anti-Prkar2b antibody and anti-flag antibody detected the protein product of cloned Prkar2b-flag.

Fig. 2. Expression of Prkar2b mRNA and protein during in vitro maturation of the oocyte. Oocytes were collected at $0 \mathrm{~h}$ (germinal vesicle, GV), 2 h (germinal vesicle break down, GVBD), 8 h (metaphase I, MI), and $16 \mathrm{~h}$ (metaphase II, MII) after incubation in M16 medium in $5 \% \mathrm{CO} 2$ at $37^{\circ} \mathrm{C}$. (A-B) RT-PCR and qRT-PCR analysis of Prkar2b at GV, GVBD, MI, and MII stages of oocyte development. H1foo was used as an oocytespecific internal control to nor-

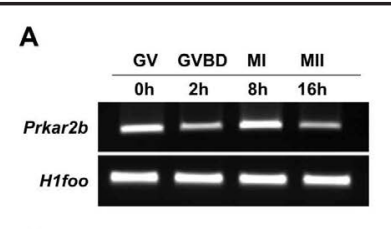

B

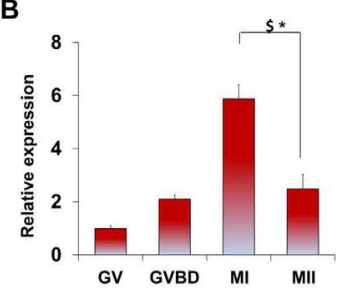

C

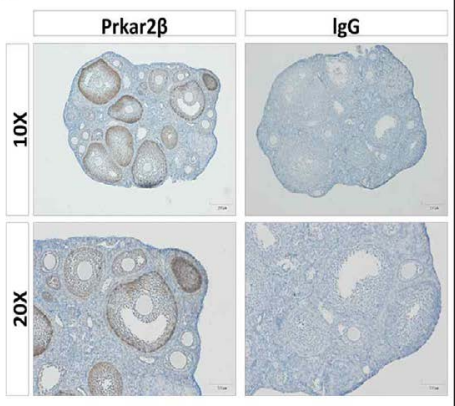

D

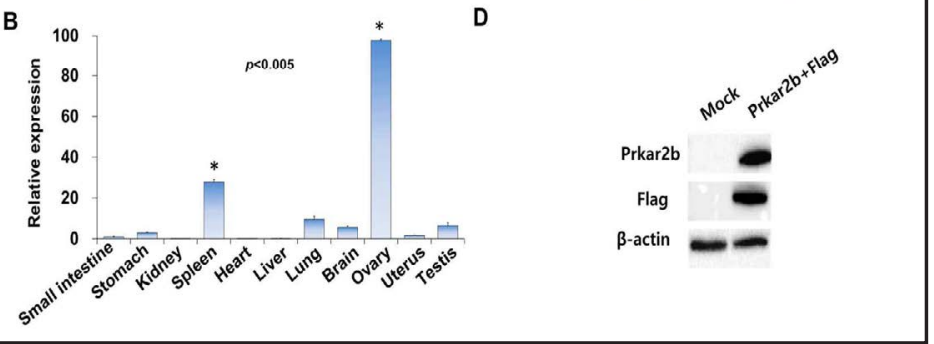
malize expression levels. Data are expressed as mean \pm SEM. The Student t-test was applied to calculate $p$-value. ${ }^{*} p<0.05, \$ p<0.05$. (C) Immunofluorescence staining of each stage of oocyte development using anti-PRKAR2B antibody. DAPI and phalloidin were used to detect chromosomes and F-actin-mediated oocyte membrane, respectively. Images were analyzed using a confocal microscope.

identify whether Prkar2b is expressed in stage of follicles of ovary, immunohistochemistry was performed. The results indicated that Prkar2b was specifically expressed in grown follicles as graffian and pre-ovulatory follicles in mouse ovary (Fig. 1C). These results suggest that Prkar2b may play an important role in the maturation process of oocyte.

\section{Expression of Prkar2b during oocyte maturation}

To examine whether Prkar2b has a critical role during oocyte maturation, Prkar $2 b$ expression levels were analyzed in the stages of oocyte maturation as GV, GVBD, MI, and MII by in vitro maturation experiment. RT-PCR and qRT-PCR showed that Prkar2 $b$ was significantly increased in the MI stage, whereas recovered during MII stage (Fig. 2A and 2B). 
Fig. 3. Construction of a dsRNAmediated Prkar2b knockdown system. (A) Schematic diagram of the mouse Prkar2b coding region. The dsRNA (Prkar2bdsRNA; location 121-669) was used for knockdown of the Prkar2b gene. A pair of primers was used to con-
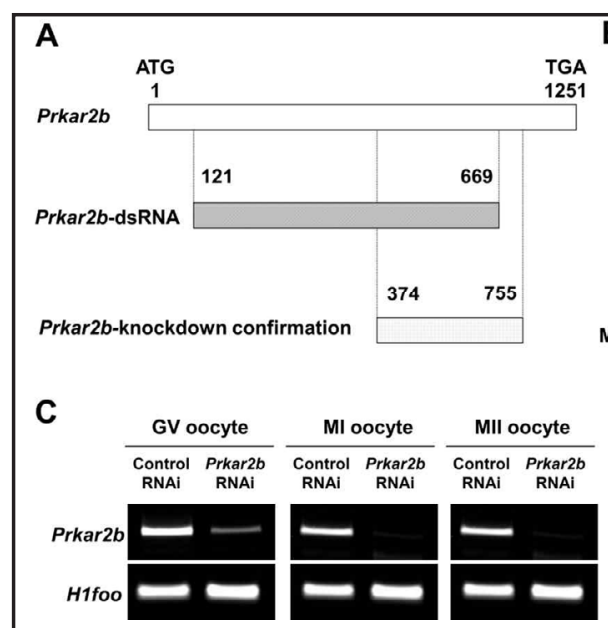

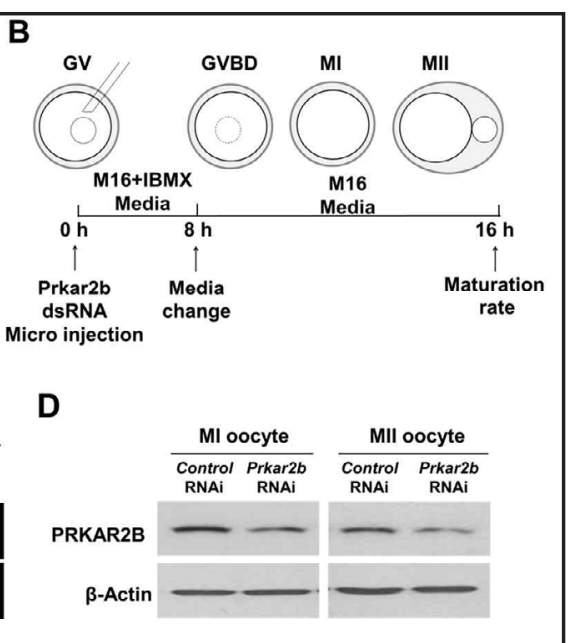

firm knockdown

of Prkar2b (location 374-755). (B) The oocyte microinjection processes. The dsPrkar2b was injected into the GV stage of the oocyte, then incubated with IBMX containing M16 media for $8 \mathrm{~h}$. After incubation, the media was replaced with M16 media to induce in vitro maturation of oocytes for $16 \mathrm{~h}$. (C) RT-PCR analysis of Prkar2b expression in control or Prkar2b RNAi-injected GV, MI, and MII oocytes. H1foo was used as an oocyte-specific internal control. (D) Western blot analysis of PRKAR2B expression in MI and MII stage oocytes. Approximately 500 microinjected oocytes were loaded for each group. $\beta$-actin was used as an internal control.

Fig. 4. Failure of meiotic division in Prkar2b-deficient oocytes. After microinjection of dsPrakr2b and dsGFP RNA, oocytes were incubated for $16 \mathrm{~h}$ to induced in vitro maturation. (A) Microphotographs of control and dsPrkar2b-injected oocytes after $16 \mathrm{~h}$. The polar body asymmetrically formed at oocytes in the control group. (B) Oocyte maturation rate of control and Prkar2b RNAi-injected oocytes. The number of Prkar2b RNAi oocytes significantly increased at MI and decreased at MII, compared to the control. (C) Time lapse video analysis of oocyte meiotic division and formation of the polar body during MII of an oocyte in a time-dependent manner.
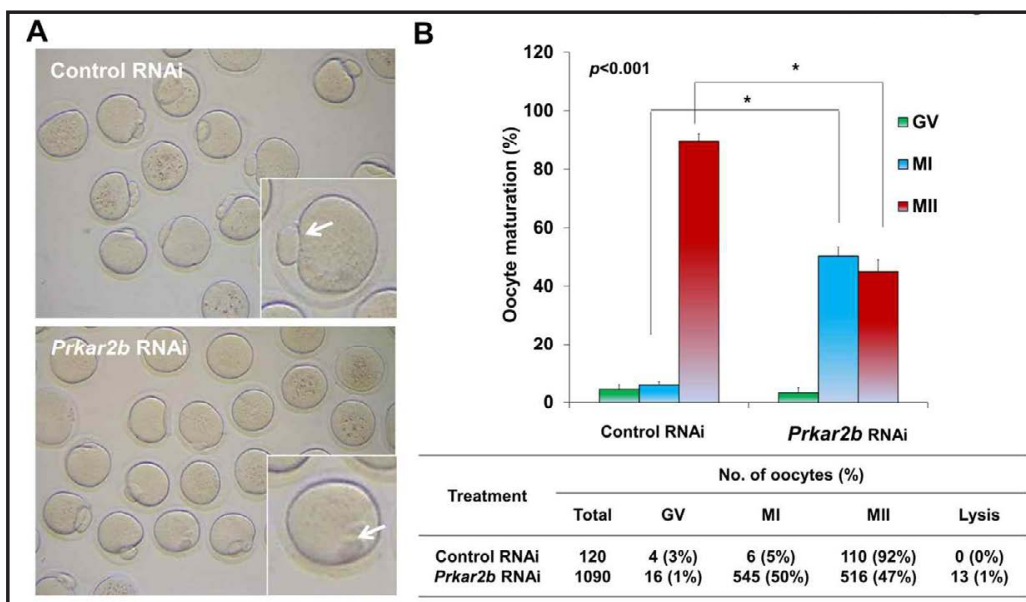

C

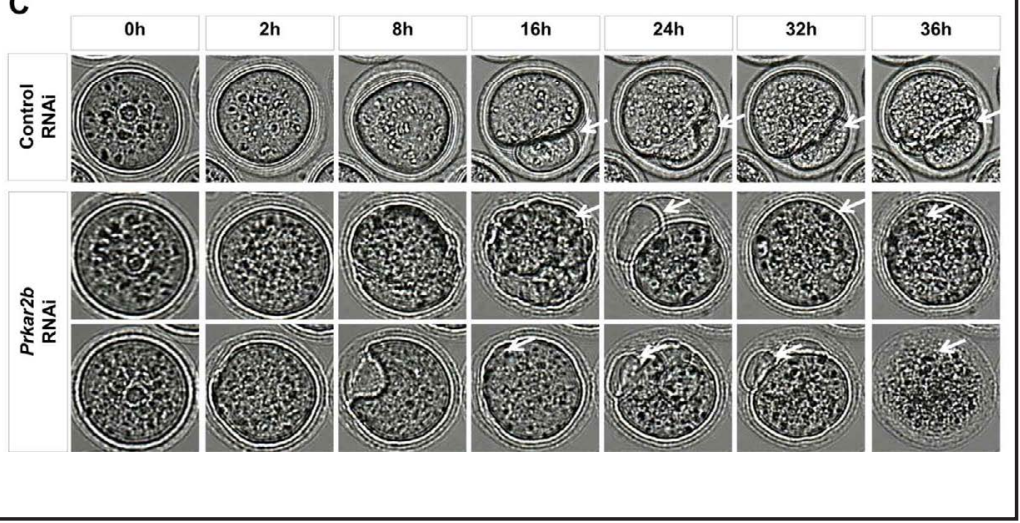




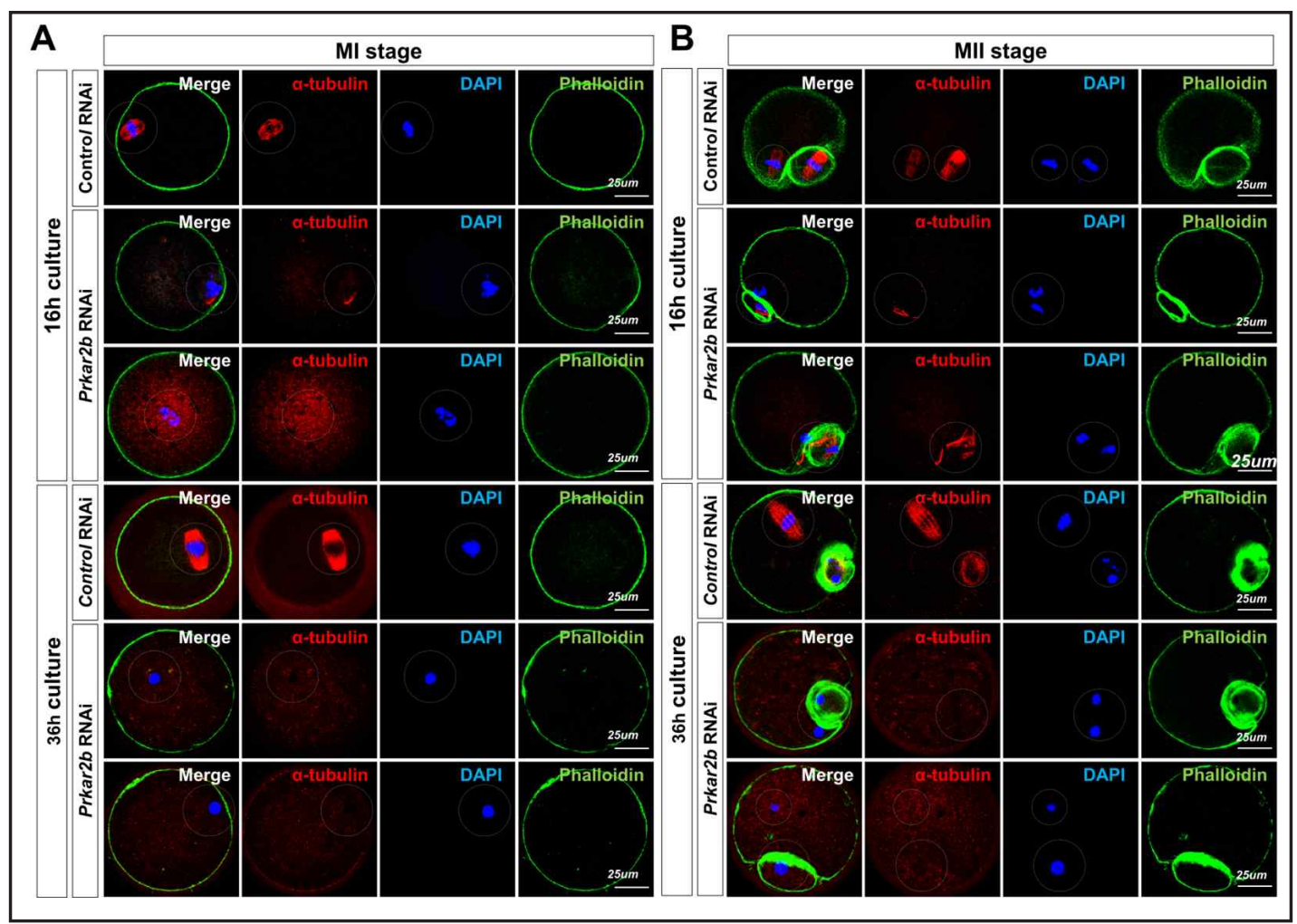

Fig. 5. Spindle formation in oocytes during MI and MII following injection of control or Prkar2b RNAi. (A) Immunofluorescence of control (dsGfp) and dsPrkar2b-injected oocytes during MI. (B) Immunofluorescence of control (dsGfp) and dsPrkar2b-injected oocytes during MII. Each stage of metaphase was divided into 16 and $36 \mathrm{~h}$. The $\alpha$-tubulin (red) is a marker of the spindle for chromosome division, and phalloidin (green) is a marker of F-actin, a structural component of the oocyte membrane. DAPI was used to detect chromosomes. The image was analyzed by confocal microscope.

To further confirm the expression of PRKAR2B protein in the stage of oocyte maturation, immunofluorescence was performed using anti-PRKAR2B antibody. As same above, the PRKAR2B expression was high in the MI stage of oocytes (Fig. 2C). These results indicate that Prkar2b may be essential to work on MI stage of oocyte.

\section{Effects of Prkar2b knockdown on oocyte maturation}

To identify the effect of inhibition of Prkar2b on oocyte maturation, double strand RNAmediated Prkar2b (dsPrkar2b) knockdown system was constructed for microinjection of oocyte. Prkar $2 b$ coding sequences were selected and the primers confirming knockdown were designed (Fig. 3A) and the process of the dsRNA microinjection was performed with control (dsGFP) and dsPrkar2b (Fig. 3B). After incubation for 16 hours, Prkar2b knockdown was confirmed during stage of oocyte maturation by RT-PCR and western blot analysis (Fig. 3C and 3D). Following dsRNA-injected oocytes maturation for $16 \mathrm{~h}$, the morphology and polar body formation were analyzed. Most of control RNAi-injected oocytes were fully matured to MII stage, whereas about half of Prkar2b RNAi-injected oocytes were arrested at MI stage (Fig. 4A and 4B). Time lapse video also showed that Prkar2b deficient oocytes were not developed and were no polar body formation compared with the control oocytes (Fig. 4C). Taken together, these results mean that deficiency of Prkar2b suppresses development of MII stage of oocyte, and Prkar2b has a critical role during polar body formation on oocyte meiotic metaphase. 


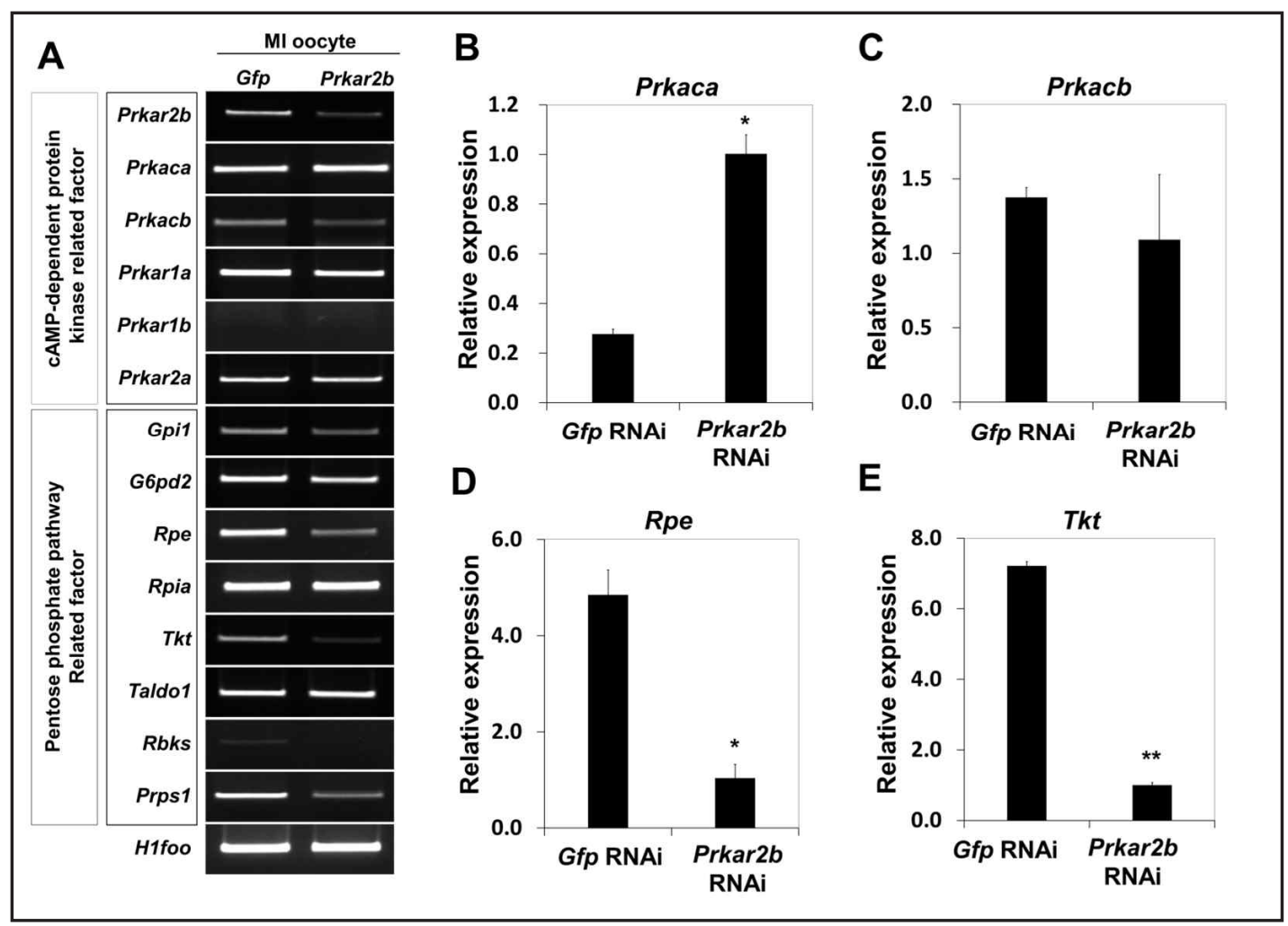

Fig. 6. Expression of PKA and the PPP-related factors in Prkar2b-knockdown oocytes. (A) RT-PCR using control and Prkar2b dsRNA-injected MI oocytes. PKA family genes, including Prkaca, Prkacb, Prkar1a, Prkar1b, Prkar2a, and Prkar2b, and PPP-related factors, including Gpi1, G6pd2, Rpe, Rpia, Tkt, Taldo1, Rbks, and Prps1 were investigated. (B-C) qRT-PCR analysis to confirm the RT-PCR of Prkaca and Prkacb. (D-E) qRTPCR analysis of Rpe and Tkt expression in Prkar2b-deficient cells. Data are expressed as mean \pm SEM. The Student t-test was applied to calculate p-value. ${ }^{*} \mathrm{p}<0.05,{ }^{* *} \mathrm{p}<0.05$.

\section{Role of Prkar2b on spindle and polar body formation during oocytes maturation}

To further confirm how Prkar2b affects polar body formation of oocyte meiosis, immunofluorescence was performed using anti-alpha tubulin antibody, a marker of spindle fiber, at MI and MII arrested oocytes after Prkar2 $b$ RNAi microinjection. In the MI stage for $16 \mathrm{~h}$ to $36 \mathrm{~h}$, the spindle was formed and the chromosomes were aligned to split, whereas in the Prkar2b suppressed oocyte, there was no spindle formation and the chromosomes were aggregated (Fig. 5A). In the MII stage, the polar body was clearly formed in the control group, while normal division by forming polar body did not occur in Prkar2b-deficient oocytes (Fig. 5B). These results suggest that Prkar2b is essential for spindle formation during oocyte maturation.

Effects of Prkar2b knockdown on the expression of cAMP-dependent protein kinase related genes and oocyte metabolism related genes.

To examine the effect of Prkar2b in the expression of PKA subfamilies, RT-PCR and qRTPCR were performed. Prkar1b and Prkar2a were showed no significant changes between control and Prkar2 $b$ RNAi treated oocytes. While Prkacb and Prkar1 $a$ were decreased, Prkaca expression was significantly increased in Prkar2b-deficient oocytes (Fig. 6A-C). Because pentose phosphate pathway (PPP) was known to control maturation and development [30], expression level of PPP-related factors, such as Gpi1, G6pd2, Rpe, Rpia, Tkt, Taldo1, Rbks, and Prps1. The expression levels of the majority of PPP-related genes were reduced in Prkar2bdeficient oocytes, especially in Rpe and Tkt cases (Fig. 6A, 6D-E). These results indicated that Prkar2b regulate oocyte maturation through controlling PPP. 


\section{Cellular Physiology Cell Physiol Biochem 2018;45:2009-2020

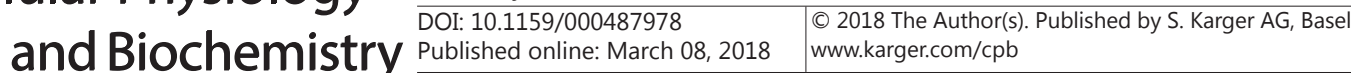 \\ Yoon et al.: PRKAR2b in Oocyte Maturation}

\section{Discussion}

Oocyte development depends on a variety of signal pathways, such as the dynamic cellular process of asymmetric meiosis. Although there are several studies regarding this signaling pathway mechanism, the oocyte maturation process has not been thoroughly described. The role of PRKAR2B (RII $\beta$ ), a regulatory isoform of PKA, in oocyte maturation, has not been studied, even though PKA signaling is known to play an important role in oocyte maturation [31-34]. Here, we investigated the expression of PRKAR2B in ovarian follicles and its critical role in oocyte development.

The few studies that explore the effects of Prkar2b signaling do so using immune cells [9, 12], nerve cells [10], and fat cells [13]. As our microarray analysis indicated that expression of Prkar $2 b$ was dramatically increased during dormant follicle maturation (data not shown), we hypothesized that PRKAR2B, a novel isoform of PKA, would be a critical regulator of follicle maturation and oocyte dormancy. As expected, we found that Prkar2b was more strongly expressed in large follicles, such as antral and pre-ovulatory follicles, than in small, growing follicles, such as primary and primordial follicles, and is also highly expressed in follicle GCs (Fig. 1C). These results suggest that PRKAR2B may be essential to follicle maturation, as well as play a role in hormonal regulation of GCs. However, further studies are needed to confirm the involvement of PRKAR2B in hormonal regulation of the reproductive system through activating ovarian GCs.

In this study, we focused on the role of PRKAR2B in oocyte maturation, as the PKA family of proteins is known to regulate maturation of oocytes [34]. Oocyte maturation involves a variety of complex procedures that may include specific factors such as PRKAR2B signaling, as well as the immune and nervous systems. Masui cited that cytostatic factor and maturationpromoting factor, major regulators of the cell cycle in oocyte maturation, are closely related to protein kinases, and the phosphorylated proteins are critical for oocyte maturation through interaction with various factors $[28,35]$. The novel protein kinase, PRKAR2B, is a possible candidate for a major regulator of the cell cycle of oocyte meiosis.

Newborn female ovaries contain their total number of oocytes, which are arrested at the diplotene stage of meiosis I until puberty, when luteinizing hormone surges induce the continuation of meiosis. In meiosis I, a diploid cell divides into two haploid cells; one becomes the secondary oocyte and the other forms the first polar body. These processes are MI to MII. We found that PRKAR2B expression peaked at MI stage of oocyte development, and then dropped to basal levels at MII stage (Fig. 2). Thus, it can be inferred that PRKAR2B plays an important role in oocyte division. These results are consistent with previous reports that various factors, including PKA family proteins, play an important role in cell division of the oocyte meiosis stage [36,37]. We also confirmed that PRKAR2B deficiency [38] results in division failure of the oocyte, as determined using time lapse video recording for $36 \mathrm{~h}$ (Fig. 4). Furthermore, Prkar2b RNAi-injected oocytes could not form the polar body through abnormal division, thus we focused on spindle formation to determine the mechanism by which this phenomenon was triggered. Immunofluorescence staining of PRKAR2B-deficient oocytes showed that the $\alpha$-tubulin assembly involved in formation of the spindle did not proceed in the MI stage. In addition, PRKAR2B deficiency also triggered abnormal formation of the secondary polar body (Fig. 5). These results indicate that one of the roles of Prkar2b is to regulate spindle formation in oocyte meiosis.

In most organisms, the PPP is essential for the synthesis of nicotinamide adenine dinucleotide phosphate (NADPH), as well as five-carbon sugars [39], nucleotides, fatty acids, and neurotransmitters [30]. Recently, several studies reported that the PPP is involved in the metabolic pathways of various cells, including cancer cells and oocytes [30, 40]. TKT, an enzyme in the PPP, plays a critical role in energy production and nucleic acid synthesis during embryonic development [41]. TKT is involved in several diseases, including Alzheimer's disease, diabetes, eye transparency, and cancer [42-44]. We found that Prkar2b deficiency results in down-regulation of Tkt mRNA expression in the MI stage of oocytes, suggesting that PRKAR2B is involved in the PPP. Furthermore, the PPP-related genes, such as Gpi1, Rpe, 


\section{Cellular Physiology Cell Physiol Biochem 2018;45:2009-2020 \begin{tabular}{ll|l} 
and Biochemistry Published onlıne: March 08, 2018 & $\begin{array}{l}\text { C } 2018 \text { The Author(s). Published by S. Karger AG, Basel } \\
\text { www.karger.com/cpb }\end{array}$ \\
\hline
\end{tabular}

and Prps1, were significantly decreased when an oocyte is deficient in Prkar2b (Fig. 6A, 6DE). Further studies are needed to understand the correlation between the PPP-mediated metabolism and PRKAR2B signaling pathway.

\section{Conclusion}

We demonstrated that Prkar $2 b$ is highly expressed in large follicles, which increased during the MI stage of the oocyte. Prkar2b deficiency triggers failure of oocyte meiotic division by suppressing formation of the spindle. In addition, PRKAR2B plays important roles in oocyte maturation through regulation of the PPP. It is the first evidence showing one of isoforms of PKA is important for oocyte maturation. The limitation of this study is that there are other isoforms expressed in the ovary. In fact, we didn't examine other's expression and location in the ovary. Also, the phenotype by knockdown of target gene will be leaky or compensated by other isoforms during oocyte maturation. We observed maturation of some oocytes under knockdown system. Therefore, we need further studies using several combinatory knockdown with Prkar2 $b$ and other members to investigate any cooperation and specificity among them during oocyte maturation. It will be give us better understanding for clinical application during in vitro fertilization in the future.

\section{Acknowledgements}

This study was supported by grants from the Basic Science Research and Priority Research Centers Program through the National Research Foundation of Korea (NRF), funded by the Ministry of Education (2009-0093821, 2016R1D1A1B03931983), and a grant from The Ministry of Science, ICT \& Future Planning (2017R1A1A11A05001385).

\section{Disclosure Statement}

The authors declare no competing financial interests.

\section{References}

1 Eid AH: cAMP induces adhesion of microvascular smooth muscle cells to fibronectin via an Epac-mediated but PKA-independent mechanism. Cell Physiol Biochem 2012;30:247-258.

$>2$ Weng L, Wang W, Su X, Huang Y, Su L, Liu M, Sun Y, Yang B, Zhou H: The Effect of cAMP-PKA Activation on TGF-beta1-Induced Profibrotic Signaling. Cell Physiol Biochem 2015;36:1911-1927.

-3 Taylor SS, Ilouz R, Zhang P, Kornev AP: Assembly of allosteric macromolecular switches: lessons from PKA. Nat Rev Mol Cell Biol 2012;13:646-658.

-4 Willis BS, Niswender CM, Su T, Amieux PS, McKnight GS: Cell-type specific expression of a dominant negative PKA mutation in mice. PLoS One 2011;6:e18772.

5 Burton KA, McKnight GS: PKA, germ cells, and fertility. Physiology (Bethesda) 2007;22:40-46.

-6 Chin KV, Yang WL, Ravatn R, Kita T, Reitman E, Vettori D, Cvijic ME, Shin M, Iacono L: Reinventing the wheel of cyclic AMP: novel mechanisms of cAMP signaling. Ann N Y Acad Sci 2002;968:49-64.

-7 Enns LC, Morton JF, Treuting PR, Emond MJ, Wolf NS, Dai DF, McKnight GS, Rabinovitch PS, Ladiges WC: Disruption of protein kinase A in mice enhances healthy aging. PLoS One 2009;4:e5963.

-8 Su J, Wu W, Huang S, Xue R, Wang Y, Wan Y, Zhang L, Qin L, Zhang Q, Zhu X, Zhang Z, Ye H, Wu X, Li Y: PKARIIB Deficiency Induces Brown Fatlike Adipocytes in Inguinal WAT and Promotes Energy Expenditure in Male FVB/NJ Mice. Endocrinology 2017;158:578-591. 


\section{Cellular Physiology Cell Physiol Biochem 2018;45:2009-2020 \begin{tabular}{ll|l} 
and Biochemistry Published online: March 08, 2018 & $\begin{array}{l}\text { C } 2018 \text { The Author(s). Published by S. Karger AG, Basel } \\
\text { www.karger.com/cpb }\end{array}$ \\
\hline
\end{tabular}

9 Tortora G, Budillon A, Yokozaki H, Clair T, Pepe S, Merlo G, Rohlff C, Cho-Chung YS: Retroviral vectormediated overexpression of the RII beta subunit of the cAMP-dependent protein kinase induces differentiation in human leukemia cells and reverts the transformed phenotype of mouse fibroblasts. Cell Growth Differ 1994;5:753-759.

10 Ohno K, Kitahara T, Takeda N, Kubo T, Kiyama H: Gene regulation of cyclic AMP-dependent protein kinase subunits (C alpha, beta; RI alpha, beta and RII alpha, beta) in rat facial motoneurons after nerve transection. Neuroscience 1994;63:1101-1109.

11 Srivastava RK, Lee YN, Noguchi K, Park YG, Ellis MJ, Jeong JS, Kim SN, Cho-Chung YS: The RIIbeta regulatory subunit of protein kinase A binds to cAMP response element: an alternative cAMP signaling pathway. Proc Natl Acad Sci U S A 1998;95:6687-6692.

-12 Elliott MR, Tolnay M, Tsokos GC, Kammer GM: Protein kinase A regulatory subunit type II beta directly interacts with and suppresses CREB transcriptional activity in activated T cells. J Immunol 2003;171:36363644 .

13 Gagliano SA, Tiwari AK, Freeman N, Lieberman JA, Meltzer HY, Kennedy JL, Knight J, Muller DJ: Protein kinase cAMP-dependent regulatory type II beta (PRKAR2B) gene variants in antipsychotic-induced weight gain. Hum Psychopharmacol 2014;29:330-335.

14 Sha J, Xue W, Dong B, Pan J, Wu X, Li D, Liu D, Huang Y: PRKAR2B plays an oncogenic role in the castrationresistant prostate cancer. Oncotarget 2017;8:6114-6129.

15 Skalhegg BS, Tasken K: Specificity in the cAMP/PKA signaling pathway. Differential expression,regulation, and subcellular localization of subunits of PKA. Front Biosci 2000;5:D678-693.

16 Zhang M, Ouyang H, Xia G: The signal pathway of gonadotrophins-induced mammalian oocyte meiotic resumption. Mol Hum Reprod 2009;15:399-409.

17 Tripathi A, Kumar KV, Chaube SK: Meiotic cell cycle arrest in mammalian oocytes. J Cell Physiol 2010;223:592-600.

18 Monniaux D, Clement F, Dalbies-Tran R, Estienne A, Fabre S, Mansanet C, Monget P: The ovarian reserve of primordial follicles and the dynamic reserve of antral growing follicles: what is the link? Biol Reprod 2014;90:85.

19 Visser JA, Themmen AP: Anti-Mullerian hormone and folliculogenesis. Mol Cell Endocrinol 2005;234:8186.

20 Peluso C, Fonseca FL, Gastaldo GG, Christofolini DM, Cordts EB, Barbosa CP, Bianco B: AMH and AMHR2 polymorphisms and AMH serum level can predict assisted reproduction outcomes: a cross-sectional study. Cell Physiol Biochem 2015;35:1401-1412.

21 Xu H, Deng K, Luo Q, Chen J, Zhang X, Wang X, Diao H, Zhang C: High Serum FSH is Associated with Brown Oocyte Formation and a Lower Pregnacy Rate in Human IVF Parctice. Cell Physiol Biochem 2016;39:677684.

-22 Pepling ME, Spradling AC: Female mouse germ cells form synchronously dividing cysts. Development 1998;125:3323-3328.

-23 Pepling ME, Spradling AC: Mouse ovarian germ cell cysts undergo programmed breakdown to form primordial follicles. Dev Biol 2001;234:339-351.

-24 Tay J, Hodgman R, Richter JD: The control of cyclin B1 mRNA translation during mouse oocyte maturation. Dev Biol 2000;221:1-9.

25 Halet G, Carroll J: Rac activity is polarized and regulates meiotic spindle stability and anchoring in mammalian oocytes. Dev Cell 2007;12:309-317.

26 Na J, Zernicka-Goetz M: Asymmetric positioning and organization of the meiotic spindle of mouse oocytes requires CDC42 function. Curr Biol 2006;16:1249-1254.

27 Yi K, Unruh JR, Deng M, Slaughter BD, Rubinstein B, Li R: Dynamic maintenance of asymmetric meiotic spindle position through Arp2/3-complex-driven cytoplasmic streaming in mouse oocytes. Nat Cell Biol 2011;13:1252-1258.

-28 Lee Y, Kim KH, Yoon H, Lee OH, Kim E, Park M, Jang H, Hong K, Song H, Ko JJ, Lee WS, Lee KA, Chang EM, Choi Y: RASD1 Knockdown Results in Failure of Oocyte Maturation. Cell Physiol Biochem 2016;40:12891302.

29 Jang H, Lee OH, Lee Y, Yoon H, Chang EM, Park M, Lee JW, Hong K, Kim JO, Kim NK, Ko JJ, Lee DR, Yoon TK, Lee WS, Choi Y: Melatonin prevents cisplatin-induced primordial follicle loss via suppression of PTEN/ AKT/FOXO3a pathway activation in the mouse ovary. J Pineal Res 2016;60:336-347. 


\section{Cellular Physiology Cell Physiol Biochem 2018;45:2009-2020

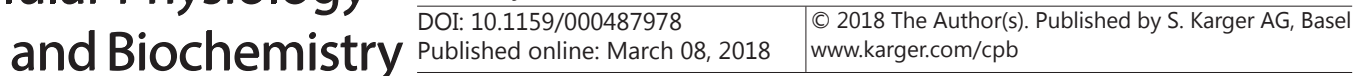

-30 Kim Y, Kim EY, Seo YM, Yoon TK, Lee WS, Lee KA: Function of the pentose phosphate pathway and its key enzyme, transketolase, in the regulation of the meiotic cell cycle in oocytes. Clin Exp Reprod Med 2012;39:58-67.

31 Duncan FE, Padilla-Banks E, Bernhardt ML, Ord TS, Jefferson WN, Moss SB, Williams CJ: Transducin-like enhancer of split-6 (TLE6) is a substrate of protein kinase A activity during mouse oocyte maturation. Biol Reprod 2014;90:63.

32 Nishimura T, Sugiura K, Naito K: A-kinase anchor protein 1 (AKAP1) regulates cAMP-dependent protein kinase (PKA) localization and is involved in meiotic maturation of porcine oocytes. Biol Reprod 2013;88:85.

-33 Pirino G, Wescott MP, Donovan PJ: Protein kinase A regulates resumption of meiosis by phosphorylation of Cdc25B in mammalian oocytes. Cell Cycle 2009;8:665-670.

34 Newhall KJ, Criniti AR, Cheah CS, Smith KC, Kafer KE, Burkart AD, McKnight GS: Dynamic anchoring of PKA is essential during oocyte maturation. Curr Biol 2006;16:321-327.

-35 Masui Y: From oocyte maturation to the in vitro cell cycle: the history of discoveries of MaturationPromoting Factor (MPF) and Cytostatic Factor (CSF). Differentiation 2001;69:1-17.

-36 Sun QY, Miao YL, Schatten H: Towards a new understanding on the regulation of mammalian oocyte meiosis resumption. Cell Cycle 2009;8:2741-2747.

-37 Chen D, Zhang Y, Yi Q Huang Y, Hou H, Zhang Y, Hao Q Cooke HJ, Li L, Sun Q, Shi Q: Regulation of asymmetrical cytokinesis by cAMP during meiosis I in mouse oocytes. PLoS One 2012;7:e29735.

38 Svoboda P, Stein P, Schultz RM: RNAi in mouse oocytes and preimplantation embryos: effectiveness of hairpin dsRNA. Biochem Biophys Res Commun 2001;287:1099-1104.

-39 Jiang P, Du W, Wu M: Regulation of the pentose phosphate pathway in cancer. Protein Cell 2014;5:592-602.

40 Patra KC, Hay N: The pentose phosphate pathway and cancer. Trends Biochem Sci 2014;39:347-354.

41 Xu ZP, Wawrousek EF, Piatigorsky J: Transketolase haploinsufficiency reduces adipose tissue and female fertility in mice. Mol Cell Biol 2002;22:6142-6147.

42 Sax CM, Salamon C, Kays WT, Guo J, Yu FX, Cuthbertson RA, Piatigorsky J: Transketolase is a major protein in the mouse cornea. J Biol Chem 1996;271:33568-33574.

43 Paoletti F, Mocali A, Tombaccini D: Cysteine proteinases are responsible for characteristic transketolase alterations in Alzheimer fibroblasts. J Cell Physiol 1997;172:63-68.

44 Cascante M, Centelles JJ, Veech RL, Lee WN, Boros LG: Role of thiamin (vitamin B-1) and transketolase in tumor cell proliferation. Nutr Cancer 2000;36:150-154. 